\title{
PREOPERATIVE ASSESSMENT OF PRIMARY VARICOSE VEINS OF LOWER LIMBS BY DUPLEX COLOR DOPPLER ULTRASOUND: A VALIDATION STUDY
}

\section{Dr. Biant Singh* \\ Dr. Manpreet Kour}

\section{Dr. Shwetabh Pradhan}

Professor and Head, Department of Surgery, VCSG Govt. MS\&RI, SrinagarGarhwal Uttarakhand-246174. *Corresponding Author

Trainee observer, VCSG Govt. MS\&RI, Srinagar-Garhwal Uttarakhand246174.

Assistant Professor, Department of Surgery, VCSG Govt. MS\&RI,SrinagarGarhwal Uttarakhand-246174.

ABSTRACT

INTRODUCTION: Varicose veins comprises a significant clinical problem representing underlying chronic venous insufficiency with ensuing venous hypertension leading to broad spectrum of clinical

manifestations.

MATERIALS AND METHOD: Our study is based on evaluation of 125 limbs in 103 patients of lower extremity symptomatic varicose veins. After establishing the nature of venous incompetence and abnormality on both clinical and duplex ultrasonography, patients were subjected to surgery and sensitivity, specificity, positive and negative predictive values and diagnostic accuracy was calculated based on operative assessments and findings.

RESULTS: Non invasive diagnostic evaluation with duplex sonography in our study proved it to be suitable procedure when sensitivity, specificity and diagnostic accuracy was assesed.

CONCLUSION: We conclude that in comparison to the cumbersome clinical assessments alone, the combination of clinical with Doppler duplex ultrasounds, proved to be more suitable and reliable procedures in avoiding the inappropriate surgeries.

KEYWORDS : Varicose vein, Doppler Duplex ultrasound, Chronic venous insufficiency, Great saphenous vein, Short saphenous vein.

INTRODUCTION:

Lower limb varicose veins represent a significant clinical problem and not just a cosmetic issue. Doppler duplex ultrasound is widely used to investigate chronic venous disease of the lower limbs and has replaced many cumbersome physiological and clinical tests. Doppler ultrasound is an essential diagnostic tool that can accurately map the origin and extent of venous reflux. The obtained hemodynamic information would permit more selective multimodal therapy and avoid indiscriminate stripping of entire saphenous system in all cases of primary varicose veins ${ }^{1}$. The incompetence at saphenopopliteal and saphenofemoral junction was mapped more accurately with duplex sonography when compared with other diagnostic methods ${ }^{2}$. It has been seen that clinical techniques were much less sensitive and specific besides having uncertainty about incompetence in upto $52 \%$ of cases ${ }^{3}$. The use of color coded Doppler scanning has resulted in change of plan of operation in sizable number of cases, if it was left to clinical tests only. The escape points would have been left intact and many a times long saphenous vein would have been stripped unnecessarily ${ }^{4}$. Color Doppler imaging helps in individualizing the treatment to cases of "lower extremity primary venous insufficiency" ${ }^{\prime \prime}$. Given the prevalence and socioeconomic impact of this disease, we validate the role of Doppler duplex ultrasonography in assessing and planning proper surgical modalities for lasting relief to our cases.

\section{MATERIALS AND METHOD:}

Our study was a prospective study conducted in the department of surgery, VCSG Govt. MS\&RI, SrinagarGarhwal Uttarakhand. The study was conducted after getting necessary approval from the ethics committee of the institution. The study was conducted between July 2018 to March 2020 on 125 limbs in 103 patients.

Inclusion Criteria-

All patients with lower limb varicose veins seeking treatment were subjects of our study.

Exclusion Criteria-

All patients with previous surgery for varicose vein (recurrent) and those found to have secondary cause of the varicose veins.

\section{METHOD -}

The patients with varicose veins seeking treatment during the time period between July 2018 to March 2020 were assessed. All of the 125 limbs in 103 patients were first assessed clinically. The following particulars of patients were noted; age, sex, residence and occupation. The history was taken regarding the nature of their symptoms, history of previous treatment, drug intake, DVT and any other risk factors. This was followed by detailed clinical examination of patients for the presence of dilated veins, edema and skin changes like pigmentation/eczema, presence of active or healed and thus clinical severity grading was done.

To know the site of incompetence this was followed by some clinical tests like Brodie Trendelenberg's test, Tourniquet tests for saphenopopliteal junction, Cough test, Schwartz test, Multiple tourniquet test and Fegan test. After the clinical assessment the patients were subjected to Duplex Color Doppler Ultrasonography. The later examination in patients with CVD was used to demonstrate both anatomical patterns of veins and abnormalities of venous blood flow in the limbs. The nature of the venous incompetence as demonstrated by the color Doppler ultrasonography was taken as the standard. The information obtained after performing various clinical tests was also used to predict specific valvular abnormality in the patient. Then different incompetent perforator sites were also marked on duplex ultrasound. After establishing nature of valvular abnormality in patient on both clinical and duplex ultrasound, they were taken for surgery. All incompetent sites detected on duplex or clinical or both examinations were operated. After obtaining information from all the patients, sensitivity, specificity, positive and negative predictive value and diagnostic accuracy were statistically calculated.

\section{OBSERVATIONS AND RESULTS:}

Out of 103 patients there were 68 males and 35 females with the difference by statistical significance at $95 \%$ confidence level. Most of our patients belonged to working age group, with mean age of 42.6 years. Duration of presentation of 
symptoms ranged from 1 year to 20 years. Majority of our patients (83 patients) presented with duration of less than 5 years of their presenting symptoms. Balateral limb involvement was seen in 22 patients and unilateral limb involvement was seen in 81 patients. Left limb was more commonly involved.

Signs observed in 125 limbs with varicose veins were dilated veins in all, edema, pigmentation, eczema, healed and active ulcers. Clinically 72 limbs belonged to C-2 severity according to CEAP system. $\mathrm{Cl}, \mathrm{C} 5$ and $\mathrm{C} 6$ were less commonly observed in less than $5 \%$ patients.

Clinical examination detected 96 SFJs and 37 SPJs in 125 limbs. It also marked 123 incompetent perforator sites in 49 limbs. [Table 1]

Table 1-Results Of Clinical Tests.

\begin{tabular}{|l|l|}
\hline Abnormality & No. of limbs \\
\hline Saphenofemoral junction & 96 \\
\hline Long saphenous vein & 26 \\
\hline Saphenopopliteal junction & 37 \\
\hline Perforators & 49 \\
\hline No. of perforators marked & 123 (sites) \\
\hline
\end{tabular}

Anatomical sites of incompetence (according to duplex) in 103 patients showed most commonly involved long saphenous venous reflux in 92 limbs followed by SFJ in 77 limbs and perforators in 53 limbs. Deep veins were least involved in 5 limbs only. [Table 2]

Table 2- Anatomical Sites Of Incompetence (according To Duplex) In 103 Patients.

\begin{tabular}{|l|l|l|}
\hline Site of incompetence & Number of limbs & \%age \\
\hline Long saphenous vein & 92 & 73.6 \\
\hline Saphenofemoral junction & 77 & 61.6 \\
\hline Short saphenous vein & 23 & 18.4 \\
\hline Saphenopopliteal junction & 34 & 27.4 \\
\hline Perforators & 53 & 42.4 \\
\hline Deep veins & 05 & 4 \\
\hline
\end{tabular}

On comparing duplex versus clinical examination in diagnosing the sites of incompetence, all incompetent SFJs and SPJs marked by duplex examinations were confirmed as incompetent on exploration. Among perforators 57 of 63 marked by both examinations were incompetent, while as, 48 out of 53 sites marked on duplex were incompetent, but , out of 60 sites marked on clinical examination alone only 12 sites were confirmed. [Table 3]

Table 3- Comparison Of Clinical And Duplex USG Versus Operative Findings.

\begin{tabular}{|c|c|c|c|c|c|c|}
\hline \multirow[t]{2}{*}{ Incompetent site } & \multicolumn{2}{|c|}{ Clinical evaluation } & \multicolumn{2}{|c|}{ Duplex evaluation } & \multirow{2}{*}{$\begin{array}{l}\text { No. of patients } \\
\text { operated }\end{array}$} & \multirow{2}{*}{$\begin{array}{l}\text { Findings } \\
\text { confirmed }\end{array}$} \\
\hline & Results & No.of limbs & Result & No. of limbs & & \\
\hline \multirow{4}{*}{$\begin{array}{l}\text { Saphenofemoral } \\
\text { junction }\end{array}$} & \multirow{2}{*}{ incompetent } & \multirow[t]{2}{*}{96} & incompetent & 68 & 68 & 68 \\
\hline & & & competent & 28 & 28 & 0 \\
\hline & \multirow[t]{2}{*}{ Competent } & \multirow[t]{2}{*}{29} & incompetent & 9 & 9 & 9 \\
\hline & & & competent & 20 & nil & nil \\
\hline \multirow{4}{*}{$\begin{array}{l}\text { Saphenopoplitea } \\
\text { l junction }\end{array}$} & \multirow{2}{*}{ incompetent } & \multirow[t]{2}{*}{37} & incompetent & 13 & 13 & 13 \\
\hline & & & competent & 24 & 24 & 0 \\
\hline & \multirow[t]{2}{*}{ Competent } & \multirow[t]{2}{*}{88} & incompetent & 21 & 21 & 21 \\
\hline & & & competent & 67 & nil & nil \\
\hline \multirow{4}{*}{$\begin{array}{l}\text { Number of } \\
\text { perforator sites } \\
\text { evaluated }\end{array}$} & \multirow[t]{2}{*}{ incompetent } & \multirow[t]{2}{*}{123} & incompetent & 63 & 63 & 57 \\
\hline & & & competent & 60 & 60 & 12 \\
\hline & \multirow[t]{2}{*}{ Competent } & \multirow[t]{2}{*}{53} & incompetent & 53 & 53 & 48 \\
\hline & & & competent & nil & nil & nil \\
\hline
\end{tabular}

On comparing sensitivity, specificity and diagnostic accuracy of duplex versus clinical examination, duplex was significantly better than clinical examination. On comparing the individual clinical tests with the duplex examination as standard, we found most tests had low sensitivity and specificity. Only trendelenburg test for SFJ had good sensitivity (89\%) but was poorly specific and tap test for LSV had high specificity. [Table 4,5]

Table 4- Comparison Between Calculated Sensitivity, Specificity, Positive Predictive Values, Negative Predictive Value And Diagnostic Accuracy Of Clinical Tests and duplex USG With Operative Finding As Gold Standard.

\begin{tabular}{|c|c|c|c|c|c|c|c|c|c|c|c|c|c|}
\hline \multirow[t]{2}{*}{ Site } & \multicolumn{2}{|c|}{ sensitivity } & \multirow[t]{2}{*}{$\begin{array}{l}\text { Value of } \\
x^{2}\end{array}$} & \multicolumn{2}{|c|}{ Specificity } & \multirow[t]{2}{*}{\begin{tabular}{|l|} 
Value of \\
$x^{2}$
\end{tabular}} & \multicolumn{2}{|c|}{$\begin{array}{l}\text { Positive } \\
\text { predictive } \\
\text { values }\end{array}$} & \multicolumn{2}{|c|}{$\begin{array}{l}\text { Negative } \\
\text { predictive } \\
\text { values }\end{array}$} & \multicolumn{2}{|c|}{$\begin{array}{l}\text { Diagnostic } \\
\text { accuracy }\end{array}$} & \multirow[t]{2}{*}{$\begin{array}{l}\text { Value of } \\
x^{2}\end{array}$} \\
\hline & \begin{tabular}{|l|} 
Clinical \\
test
\end{tabular} & duplex & & \begin{tabular}{|l|} 
Clinical \\
test
\end{tabular} & duplex & & \begin{tabular}{|l|} 
Clinical \\
test
\end{tabular} & duplex & \begin{tabular}{|l}
$\begin{array}{l}\text { Clinical } \\
\text { test }\end{array}$ \\
\end{tabular} & duplex & \begin{tabular}{|l|}
$\begin{array}{l}\text { Clinical } \\
\text { test }\end{array}$ \\
\end{tabular} & duplex & \\
\hline SFJ & \begin{tabular}{|l|}
88.3 \\
\end{tabular} & 100 & 7.6 & \begin{tabular}{|l|l}
41.6 \\
\end{tabular} & 100 & 22.9 & \begin{tabular}{|l|}
70.8 \\
\end{tabular} & 100 & 69 & 100 & \begin{tabular}{|l|}
70.4 \\
\end{tabular} & 100 & 29.9 \\
\hline SPJ & 38.2 & 100 & \begin{tabular}{|l|}
14.3 \\
\end{tabular} & 73.6 & 100 & 25.7 & 35.1 & 100 & 76.1 & 100 & 64 & 100 & 44.3 \\
\hline $\begin{array}{l}\text { Perforat } \\
\text { ors } \\
\text { marked }\end{array}$ & 59.0 & 89.7 & 42.1 & 81.4 & 81.4 & 52.4 & 57.5 & 90.5 & N.A & N.A & 39.2 & 86.9 & \begin{tabular}{|l|}
77.4 \\
\end{tabular} \\
\hline
\end{tabular}

Table 5 - Comparison Of Individual Clinical Tests Compared With Duplex.

\begin{tabular}{|c|c|c|c|c|}
\hline \multirow[t]{2}{*}{ Test applied /site examined } & \multicolumn{2}{|c|}{ Clinical evaluation } & \multicolumn{2}{|c|}{ Duplex evaluation } \\
\hline & Results & No. of limbs & Results & No. of limbs \\
\hline \multirow{4}{*}{$\begin{array}{l}\text { Modified trendelenburg/ } \\
\text { tourniquet test (SFJ) }\end{array}$} & \multirow[t]{2}{*}{ Incompetent } & \multirow[t]{2}{*}{96} & Incompetent & 68 \\
\hline & & & Competent & 28 \\
\hline & \multirow[t]{2}{*}{ Competent } & \multirow[t]{2}{*}{29} & Incompetent & 9 \\
\hline & & & Competent & 20 \\
\hline \multirow[t]{4}{*}{ Cough test (SFJ) } & \multirow[t]{2}{*}{ Incompetent } & \multirow[t]{2}{*}{58} & Incompetent & 42 \\
\hline & & & Competent & 16 \\
\hline & \multirow[t]{2}{*}{ Competent } & \multirow[t]{2}{*}{67} & Incompetent & 35 \\
\hline & & & Competent & 32 \\
\hline \multirow{2}{*}{$\begin{array}{l}\text { Tap test (long saphenous } \\
\text { vein) }\end{array}$} & \multirow[t]{2}{*}{ Incompetent } & \multirow[t]{2}{*}{26} & Incompetent & 23 \\
\hline & & & Competent & 3 \\
\hline
\end{tabular}




\begin{tabular}{|l|l|l|l|l|}
\hline & Competent & 99 & Incompetent & 69 \\
\cline { 3 - 5 } & & & Competent & 30 \\
\hline Perforator incompetence & Incompetent & 49 & Incompetent & 27 \\
\cline { 2 - 5 } & & & Competent & 22 \\
\cline { 2 - 5 } & & 22 & Incompetent & 26 \\
\cline { 3 - 5 } & & Competent & 50 \\
\hline $\begin{array}{l}\text { Clinical tests for perforators } \\
\text { (MMT, fegan's test) }\end{array}$ & Incompetent & 123 & Incompetent & 69 \\
\cline { 2 - 5 } & Competent & 53 & Competent & 54 \\
\hline
\end{tabular}

\section{DISCUSSION:}

In our study when comparing the clinical findings and the color Doppler duplex ultrasound results we found 28 SFJs were unnecessarily explored and 9 SFJs would have been missed on clinical grounds alone. Similarily 24 SPJs were unnecessarily explored and 21 SPJs would have been left untreated on clinical basis alone. For perforators 59 sites were unnecessarily explored and 49 would have been left untreated on clinical grounds, while as on the basis of duplex 12 would have been missed and 11 sites explored unnecessarily. Our study demonstrated that on basis of clinical examination alone a large number of surgeries were done unnecessarily and many sites would have been missed bearing few perforated sites missed or wrongly explored on duplex USG basis. Our findings of high sensitivity and specificity for Duplex in detecting SFJs and SPJs incompetence are in accordance with the study done by Dixon $\mathrm{PM}^{6}$ and GWL Philips ${ }^{7}$.

So far as establishing a diagnosis of SFJ incompetence clinical examination was $88.4 \%$ sensitive and $41.6 \%$ specific when compared to $100 \%$ specificity and sensitivity of duplex which is in accordance with the study done by Benabou JE et $\mathrm{al}^{8}$ and MG Vashisht ${ }^{9}$.

We have found clinical examination was $38.2 \%$ sensitive and $73.6 \%$ specific in detecting SPJs incompetence when checked intraoperatively as compared to $100 \%$ sensitivity and specificity of duplex. Similar results were observed in study of M G Vashisht ${ }^{9}$.

While evaluating the sensitivity and specificity of duplex and clinical examination for perforator incompetence the clinical examination had $59 \%$ sensitivity and $18.5 \%$ specificity in comparison to $89.7 \%$ sensitivity and $81.5 \%$ specificity for duplex. Similar results were obtained in results of Perik EJM ${ }^{10}$ and M G Vashisht ${ }^{9}$.

Individual clinical tests had low sensitivity and specificity in detecting incompetent sites which is in accordance with the studies done by W H Hoffman ${ }^{11}{ }^{,} \mathrm{J} \mathrm{Kim}{ }^{12}$ and Mc Irvine ${ }^{13}$.

The results of our study favour the role of duplex ultrasound in establishing the diagnosis, assessing the severity of reflux, incompetence and determining the anatomy while planning surgeries for symptomatic lower limb varicose veins avoiding unnecessary and wrong surgeries besides preventing the reoccurrence.

\section{CONCLUSION:}

Varicose veins is a common pathological entity affecting the lower limbs, most commonly in men in our society in working age groups presenting as a spectrum of disease from mildly symptomatic visible veins to disability related refractory venous ulcers. Clinical examination misses many incompetent SFJs, SSPJs and perforators, while as labelling a number of incompetent sites as competent. Hence clinical examination alone is not sufficient in guiding the treatment plan for varicose veins and so the Venous duplex imaging which combines B mode imaging of deep and superficial veins with pulsed Doppler assessment of flow is a well established method to plan management for symptomatic varicose veins besides excluding acute venous problems like DVT, thus making it a gold standard and main stay non invasive evaluation of chronic venous insufficiency.

What the study adds to the existing knowledge? The description of lower limb venous anatomy demonstrated by ultrasound imaging is intended to be the basis for future research regarding the morphology of healthy and diseased, superficial and perforating veins.

\section{Author's contribution:}

Prof.(Dr.)Biant Singh: Conceptualized the study, Principal investigator, prepared the study protocol, participated in data collection, entry, preparation and editing of all drafts.

Dr. Manpreet Kour: Co -investigator,data collection, manuscript preparation.

Dr. Shwetabh Pradhan: Co- investigator, Review of literature and preparation of the drafts.

\section{Funding: No funding sources}

\section{Conflict of interest: None declared}

Ethical Approval: This study was approved by the Institutional Ethics Committee

\section{REFERENCES:}

1. Goren G, Yellin AE. Primary varicose veins: topographic and hemodynamic correlations. The journal of cardiovascular surgery 1990; 31(5): 627-7.

2. Bork-Wolwer L, Wuppermann T. Improvement in non-invasive diagnosis of the greater and lesser saphenous vein insufficiency with duplex sonography. Vasa.1991;20(4):343-7

3. Rautio T, Perala J, Biancari F, Wiik H, Ohtonen P, Haukipuro K, Juvonen T; Accuracy of hand held Doppler in planning the operation for primary varicose veins. European journal of vascular and endovascular surgery 2002; 24:450-5.

4. Van der Heijden FH, Bruyninckx CM. Preoperative color- coded duplex scanning in varicose veins of the lower extremity. Eur J Surg.1993 Jun-Jul; 159(6-7):329-33

5. Asterios N. Katsamouris, Demetrios G Kardoulas and Nicholas Gourtsoyiannis. The nature of lower extremity venous insufficiency in patients with primary varicose veins. European journal of vascular surgery June 1994:8(4):464-71

6. Dixon PM. Duplex ultrasound in the pre-operative assessment of varicose veins. Australas Radiol.1996;40(4):416-21

7. G.W.L Philips,J. Paige and MP Molan. Comparison of color duplex ultrasound with venography and varicography in the assessment of varicose veins. Clinical radiology.1995:50(1):20-25

8. Benabou JE,Molnar LJ,Cerri GG.Duplex sonographic evaluation of the saphenofemoral venous junction in patients with recurrent varicose veins after surgical treatment. JClin Ultrasound. 1998;26(8):401-4

9. M.G.Vashisht, R.Godara, J.Sen, S. Panwar. Management of varicose veins: status of clinical examination and color Doppler in present Indian scenario. Internet journal of surgery 2009;20(1)

10. E.G.J.M Pierik, IM Toonder,H Van Urk, C.H.A Wittens. The Validation of duplex Ultrasonography in detecting competent and incompetent perforating veins in patients with venous ulceration of the lower leg. JVasc Surg 1997;26:49-52.

11. W H Hoffman, IMM Toonder, C HA Wittens. Value of trendelenburg tourniquet test in the assessment of primary varicose veins. Phelebology 2004;19:77-80

12. J Kim, S Richards, PJ Kent.clinical examination of varicose veins- a validation study. Ann R Coll Surg Engl. 2000;82(3): 171-175

13. A JMc Irvine, C R R Corbett, N O Aston, E A Sheriff, E A Wiesman. Demonstration of saphenofemoral incompetence Doppler ultrasound compared with standard clinical tests. British Journal of surgery;71(7): 709-710. 